\title{
Methadone deaths: a toxicological analysis
}

\author{
C M Milroy, A R W Forrest
}

\begin{abstract}
Aims-To perform a toxicological analysis of deaths involving methadone and to determine the fatal concentration of methadone in such deaths.

Methods-Deaths in which methadone was mentioned in the cause of death were identified. Deaths were divided into those associated with methadone only and deaths in which the cause of death was a combination of methadone and other drugs. Toxicological findings in these deaths were analysed and compared with previously published data.

Results-One hundred and eleven cases were analysed. In 55 cases, methadone poisoning was given as the sole cause of death. Fifty victims were adults, age range 17-51 years (median, 23), with five victims under 14 years of age. The mean methadone concentration in the adult deaths was $584 \mu \mathrm{g} /$ litre (median, 435; range, 842700). In 56 cases, age range 15-49 years, (median, 28), death was ascribed to a combination of methadone and other drugs. The mean methadone concentration in these deaths was $576 \mu \mathrm{g} /$ litre (median, 294; range, 49-2440). In 26 cases, multiple site sampling was performed. This revealed that there could be a $100 \%$ discrepancy between methadone concentrations, and other drugs, in samples collected in different sites in the same body.

Conclusions-There is an overlap between quoted therapeutic methadone concentrations and methadone concentrations seen in fatalities. However, those dying from methadone poisoning might not be the same as those in a methadone programme. A degree of caution must be exercised in determining a fatal concentration because of the phenomenon of postmortem redistribution. Pathologists and toxicologists need to examine all the available postmortem findings in identifying the cause of death. (F Clin Pathol 2000;53:277-281)
\end{abstract}

Department of Forensic Pathology, University of Sheffield, Sheffield, The

Medico-Legal Centre, Watery Street, Sheffield S3 7ES, UK

C M Milroy

A R W Forrest

Correspondence to: Dr Milroy

emai:

C.M.Milroy@Sheffield.ac.uk

Accepted for publication 20 October 1999 Methadone is the standard drug used in the maintenance of opiate addiction and has been so since the pioneering work of Vincent Dole and Marie Nyswander in the 1960s. ${ }^{1}$ Methadone is used because studies have shown that it reduces the illicit use of opiates, and associated acquisitive crime. Methadone maintenance programmes have also been shown to reduce the risks of acquiring human immuno- deficiency virus (HIV) infection and its attendant medical and social problems. They allow many patients to maintain normal social activity.

The UK has always had what is considered in the medical world to be a liberal pattern of prescribing in drug addiction, with less regulation than many other countries. ${ }^{2}$ The ability to prescribe whatever a physician believed was appropriate for his patient, be it heroin, cocaine, or injectable methadone has become known as the "British system". In 1968, physicians treating patients with heroin and cocaine were required to obtain a license from the Home Office, but methadone can be prescribed by any registered medical practitioner. Although heroin (diamorphine), cocaine, and injectable methadone were the original mainstay of opiate addiction treatment, oral methadone has become the standard drug of choice, although other drugs such as dihydrocodeine, buprenorphine, lofexidine, and naltrexone are also used, as well as heroin and injectable methadone.

In the UK, there are an estimated 150000 opiate addicts, which is one in 380 of the population. Overall in Europe, the addiction rate is one in 400, with an estimated 1000000 addicts. In the USA, the rate of opiate addiction is one in $250 .^{3}$ There are 26000 opiate addicts in methadone maintenance programmes in the UK, which comprises $17 \%$ of all known opiate addicts. Between 1981 and 1989 , under $100 \mathrm{~kg}$ of methadone were prescribed each year in the UK, but by 1994 the figure was over $500 \mathrm{~kg}{ }^{3}$ With this increase in methadone prescribing, an increasing number of deaths associated with methadone has been recorded in England and Wales. ${ }^{4}$ Overall in western Europe, there was a sixfold increase in methadone dispensed between 1981 and 1994. More methadone for each head of population is prescribed in Denmark, Switzerland, and the Netherlands, but the other western European countries prescribe less. ${ }^{3}$ A recent survey in the UK of community (high street) pharmacies dispensing methadone showed that of NHS prescriptions $79.6 \%$ were for the oral liquid, $11 \%$ for tablets, and $9.3 \%$ for injectable methadone. Private prescriptions showed a different pattern, with 33\% for tablets, 33\% for injectable methadone, and only $35 \%$ for oral liquid. ${ }^{5}$

Methadone is a synthetic diphenylpro- pylamine and is similar in structure to acetylmethadol and propoxyphene. Although it is chemically different from morphine, it has clinically similar actions and analgesic effects. It is well absorbed from the gastrointestinal tract and 30 minutes after ingestion of a therapeutic dose measurable amounts are present in 
plasma. Peak plasma concentrations after therapeutic doses occur within 2-4 hours. Typically, it has a long half life of 10-18 hours, but it can be as much as 25 hours or longer. Clinical effects can last up to 72 hours in some subjects after a single oral dose. Because of the long half life methadone can be prescribed just once daily. Methadone does not produce the instant euphoria of heroin.

Methadone is available in several preparations in the UK. It is available in an injectable form at $10 \mathrm{mg} / \mathrm{ml}$, with ampoules available that contain $1 \mathrm{ml}(10 \mathrm{mg}), 2 \mathrm{ml}(20 \mathrm{mg}), 3.5 \mathrm{ml}$ (35 mg), and $5 \mathrm{ml}(50 \mathrm{mg})$. In tablet form it is available as a $5 \mathrm{mg}$ formulation. It is also available as an oral liquid, where it has a concentration of $1 \mathrm{mg} / \mathrm{ml}$. An oral concentrate in $10 \mathrm{mg} /$ litre and $20 \mathrm{mg} /$ litre strengths is also available. This should be diluted by the dispenser, with the final concentration being specified on the bottle. A sugar free preparation is available.

In opiate addiction, a characteristic starting dosage is $10-20 \mathrm{mg} /$ day, with experienced users taking $40-100 \mathrm{mg} / \mathrm{day}$, and some as much as $180 \mathrm{mg} /$ day. Plasma concentrations of 150-200 $\mu \mathrm{g} /$ litre are sufficient to control withdrawal, and maintenance concentrations should be above $400 \mu \mathrm{g} /$ litre..$^{6-8}$

Fatal postmortem concentrations have variously been quoted as 220-3040 $\mu \mathrm{g} / \mathrm{litre}$ (mean, 1371), ${ }^{9}$ 200-4500 $\mu \mathrm{g} /$ litre (mean, 800 ), ${ }^{10} 320-2980 \mu \mathrm{g} /$ litre (mean, 772), ${ }^{11}$ and 1000-2000 $\mu \mathrm{g} /$ litre. $^{12}$ Segal and Catherman quoted concentrations of $100-2500 \mu \mathrm{g} /$ litre (mean, 1100) for deaths after intravenous administration and $100-2600 \mu \mathrm{g} /$ litre (mean, 393) after oral administration. They included a few deaths with no recorded blood methadone concentrations, which have been excluded from the figures above. They found ranges of $200-400 \mu \mathrm{g} /$ litre in eight patients in a methadone programme. ${ }^{13}$ Worm and colleagues examined a series of methadone deaths, dividing deaths into those with no blood alcohol and those with a blood alcohol above $50 \mathrm{mg} / 100 \mathrm{ml}^{14}$ Of 59 methadone deaths with no alcohol, the methadone range found was 60-3090 $\mu \mathrm{g} /$ litre (median, 280; mean, 430). Of eight deaths with alcohol, the range was 90-650 $\mu \mathrm{g} /$ litre (median, 150; mean, 250). They also compared 11 deaths in people in a methadone programme with 11 deaths in people not in any such programme. The blood methadone range in those on treatment was 30-1240 $\mu \mathrm{g} /$ litre (median, 430; mean, 470). In those not in a maintenance programme, the methadone range was 30 $990 \mu \mathrm{g} /$ litre (median, 220; mean, 270). They also examined methadone concentrations in living addicts. In 62 patients with no alcohol the range of methadone concentrations was 30-560 $\mu \mathrm{g} /$ litre (median, 110; mean, 140). In 35 addicts with alcohol present the range was 30-900 $\mu \mathrm{g} /$ litre (median, 90; mean, 150). In an analysis of 104 living addicts, Loimer and Schmid found a plasma methadone range of 20-1308 $\mu \mathrm{g} /$ litre (mean, 451.4; SD, 306.6) after a mean (SD) oral methadone dose of $83.3 \mathrm{mg}$ (32.4). ${ }^{7}$ These studies indicate that there is an overlap between therapeutic concentrations and those recorded in some methadone fatalities.

Pathologists have been criticised for over diagnosing deaths from methadone poisoning because of the recorded overlap between clinical and postmortem methadone concentrations. ${ }^{15}$ We present the toxicological data on a series of methadone deaths, and also discuss the problems in analysing postmortem methadone concentrations.

\section{Materials and methods}

The department of forensic pathology, University of Sheffield examines all suspicious deaths in the North, South, and West Yorkshire, Humberside, and Nottinghamshire constabulary areas. In addition, all drug related deaths in Sheffield and in the Humberside constabulary area are examined. Other drug related deaths are examined from time to time at the request of various coroners and other agencies. All cases in which methadone was mentioned in the cause of death between 1991 and July 1999 were identified. In all but two cases, the toxicological analysis was performed by the toxicology section of the department of clinical chemistry of the Royal Hallamshire Hospital, Sheffield. In every death a full postmortem examination was performed with histology and toxicology. Peripheral venous blood, urine, and stomach contents where available were sent for toxicological analysis. In two cases, decompositional changes meant only pleural cavity fluid was available. In 26 cases multiple site sampling was performed.

\section{Results}

In total, 111 cases were identified. Of these deaths, five were under 14 years of age. Table 1 gives the toxicology results of deaths in children. These results have been excluded from the analysis of the adult results.

Of the adult deaths, there was evidence of intent to commit suicide in two cases. In three cases death occurred while the person was in lawful custody. One person had been arrested for a drink related charge, but was in fact intoxicated with methadone and benzodiazepines. The other two were in prison. One obtained the methadone illegally, but the other methadone was lawfully prescribed. In 55 cases, methadone was the only drug mentioned in the cause of death. Five were the children described above. Of the 50 adult victims (46 men, four women), the age range of the victims was $17-51$ years (mean, 25.2; median, 23). The methadone concentration range in these cases was $84-2700 \mu \mathrm{g} /$ litre (mean, 584; median, 435; interquartile range, 281 to 713 ). In 20 of the 50 cases, morphine was present in the blood in low concentrations; in only five cases was the concentration above $25 \mu \mathrm{g} /$ litre, the highest being $99 \mu \mathrm{g} /$ litre. The other principal drugs found were diazepam (23), temazepam (10), alcohol (nine), cyclizine (seven), other opiates (six), and cocaine (one). In the cases where benzodiazepines were present, only four had concentrations above $500 \mu \mathrm{g} /$ litre, the highest being $923 \mu \mathrm{g} /$ litre. In addition, benzodiazepines were 


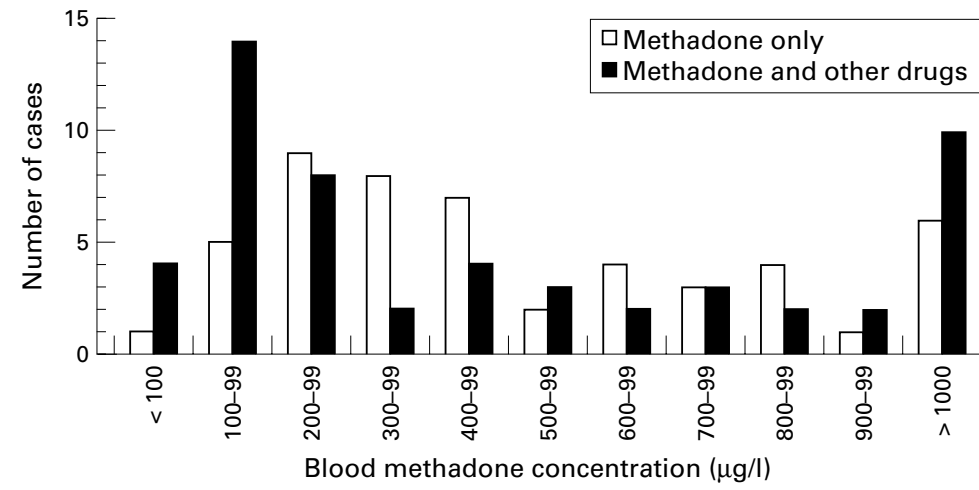

Figure 1 The distribution of blood methadone concentrations in cases where death was caused by methadone only and in cases where death was the result of a combination of methadone and other drugs.

Table 2 Toxicological findings in multiple site sampling

\begin{tabular}{|c|c|c|c|c|c|c|c|c|}
\hline \multirow{2}{*}{$\begin{array}{l}\text { Case } \\
\text { (sex) }\end{array}$} & \multicolumn{2}{|c|}{ Methadone $(\mu \mathrm{g} / \mathrm{l})$} & \multicolumn{2}{|c|}{ Temazepam $(\mu g / l)$} & \multicolumn{2}{|c|}{ Diazepam $(\mu g / l)$} & \multicolumn{2}{|c|}{ Morphine $(\mu g / l)$} \\
\hline & Arm & Leg & Arm & Leg & Arm & Leg & Arm & Leg \\
\hline $3(M)$ & 489 & 380 & - & - & - & - & - & - \\
\hline $15(\mathrm{M})$ & 101 & - & - & - & - & - & 525 & 375 \\
\hline $20(\mathrm{~F})$ & 447 & 349 & 659 & 846 & $<50$ & $<50$ & 165 & 145 \\
\hline $21(\mathrm{M})$ & 290 & 140 & - & - & 301 & 173 & 85 & 65 \\
\hline $22(\mathrm{~F})$ & 643 & 129 & - & - & - & - & 42 & 39 \\
\hline $22(\mathrm{M})$ & 840 & 716 & - & - & 161 & 125 & 48 & $<25$ \\
\hline $23(\mathrm{M})$ & 1079 & 576 & - & - & 578 & 330 & $<25$ & $<25$ \\
\hline $24(\mathrm{M})$ & 224 & 201 & 210 & - & - & - & 217 & 181 \\
\hline $24(\mathrm{M})$ & 361 & 161 & - & - & 328 & 384 & - & - \\
\hline $24(\mathrm{M})$ & 101 & 94 & - & - & 94 & 117 & 184 & 188 \\
\hline $25(\mathrm{M})$ & 1570 & 1290 & 1305 & - & 408 & - & $<25$ & $<25$ \\
\hline $26(\mathrm{M})$ & 353 & 288 & 86 & 44 & 330 & 267 & - & - \\
\hline $27(\mathrm{M})$ & 489 & 572 & 1231 & 796 & - & - & $<25$ & $<25$ \\
\hline $29(\mathrm{M})$ & 1235 & 980 & 3010 & 1500 & - & - & $<25$ & $<25$ \\
\hline $29(\mathrm{M})$ & 464 & 322 & Trace & Trace & Trace & Trace & $<25$ & $<25$ \\
\hline $29(\mathrm{M})$ & 537 & 478 & 3080 & - & - & - & $<25$ & $<25$ \\
\hline $30(\mathrm{M})$ & 2040 & 1210 & - & - & - & - & 244 & - \\
\hline $31(\mathrm{M})$ & 835 & 814 & 1502 & 1449 & - & - & 108 & 147 \\
\hline $34(\mathrm{M})$ & 1500 & 1500 & 1200 & - & - & - & - & - \\
\hline $34(\mathrm{M})$ & 142 & 70 & - & - & - & - & - & - \\
\hline $35(M)$ & 1800 & 2200 & $<100$ & $<100$ & 449 & 398 & $<25$ & $<25$ \\
\hline $36(\mathrm{M})$ & 478 & 586 & 1086 & 1493 & - & - & $<25$ & $<25$ \\
\hline $37(\mathrm{M})$ & 1810 & 2440 & - & - & - & - & 63 & 136 \\
\hline $37(\mathrm{M})$ & 856 & 836 & - & - & 144 & 183 & 62 & 96 \\
\hline $40(\mathrm{M})$ & 1640 & 930 & 1028 & - & - & - & $<25$ & $<25$ \\
\hline $40(\mathrm{~F})$ & 139 & 104 & - & - & - & - & - & - \\
\hline
\end{tabular}

$\mathrm{F}$, female, $M$, male.

detected in the urine, but not blood, in seven cases. Cannabinoids were detected in the urine in 20 cases. Amphetamines were found in five cases.

In 56 cases, death was determined to be the result of a combination of methadone and other drugs. There were 43 male and 13 female victims, age range 15-49 years (mean, 29.3; median, 28). In 54 cases, methadone was listed in the main cause of death. In the other two cases methadone was recorded in part II of the death certificate. Of these 54 cases, two involved measurements of pleural cavity fluid. In the remaining 52 cases, the range of blood methadone concentration was $49-2440 \mu \mathrm{g} /$ litre (mean, 576; median, 294; interquartile range, 142 to 877 ). Methadone was recorded along with one other drug in 29 victims; heroin in 12 cases (mean, $355 \mu \mathrm{g} /$ litre) alcohol in six cases (mean, $179 \mathrm{mg} / 100 \mathrm{ml}$ ), temazepam in six cases (mean, $1351 \mu \mathrm{g} /$ litre), cyclizine (two cases), chlorpromazine (one case), dextromoramide (one case), and dothiepin (one case). In the remaining cases there was a mixture of three or more drugs, the principal associated substances being temazepam in 17 cases (mean, $1351 \mu \mathrm{g} /$ litre), heroin in nine cases (mean, $542 \mu \mathrm{g} /$ litre), cyclizine in seven cases (mean, $1820 \mu \mathrm{g} /$ litre), diazepam in five cases (mean, $738 \mu \mathrm{g} /$ litre), dihydrocodeine (three cases), and morphine (two cases). In addition, in 21 cases cannabinoids were detected in the urine and in eight cases codeine was also present. Amphetamines were found in six cases, with the drug being included in the cause of death in two. Cocaine or its metabolites were found in four cases. Antidepressant use was found in 12 of the 111 cases. MDMA (commonly known as "ecstasy") was encountered in only one case.

Figure 1 shows the range of methadone concentrations in cases where death was caused by methadone only and in cases where death was the result of a combination of methadone and other drugs.

Stomach contents were examined for methadone in 94 cases. In two cases none was detected. In 60 cases, the methadone concentration was less than $10 \mathrm{mg} /$ litre. In 26 cases, it was between 10 and $49 \mathrm{mg} /$ litre, in three cases between 50 and $99 \mathrm{mg} /$ litre, and in three cases over $100 \mathrm{mg} /$ litre.

Bronchopneumonia was identified in 25 of the deaths ascribed to methadone only and in 11 of the cases where death was caused by methadone and other drugs. This is a significant difference $(\mathrm{p}<0.01)$

In 26 cases, multiple site sampling was performed (table 2). These data illustrate the problems associated with interpreting postmortem toxicological data. In the context of the findings in the cases in this study, the highest value has been used in the results described above. No particular site emerges as the most suitable to sample, but values of methadone, as well as other drugs, can vary by over $100 \%$ between different sites in the same body.

\section{Discussion}

Methadone maintenance programmes are established in many countries as the treatment of choice in opiate addiction. However, methadone is now well recognised as a significant poison in both opiate addicts and in other subjects who are exposed to diverted methadone. ${ }^{4-22}$ Since the start of methadone programmes and the increase in prescriptions for methadone, reports have appeared detailing methadone deaths. In early studies, the problems of inappropriate prescribing and uncontrolled dispensation were identified. More recent studies have identified the problems of naive users, highlighting the deaths of those entering methadone programmes and those who have obtained diverted methadone. Both an earlier study from Sheffield and a study from Manchester revealed that half the deaths from methadone poisoning were from diverted methadone. ${ }^{17}{ }^{18}$

Pathologists and toxicologists have been criticised for over diagnosing methadone poisoning as a cause of death, on the basis that concentrations recommended for maintenance treatment are above those at which death will be ascribed to methadone poisoning. ${ }^{15}$ This criticism requires explanation. As can be seen 
in our series, many of the deaths have been recorded as methadone deaths with postmortem whole blood concentrations below $400 \mu \mathrm{g} /$ litre. Indeed, the median value in methadone only deaths was $435 \mu \mathrm{g} /$ litre. In combination polydrug deaths the median methadone value was lower, but the means in both series were similar. These figures are based on whole blood analysis. The ratio of plasma to whole blood in antemortem samples is 1 to 1.3 . Applying this conversion factor to postmortem blood would imply that the median concentration for methadone in whole blood of $435 \mu \mathrm{g} /$ litre would equate to a plasma concentration of $335 \mu \mathrm{g} /$ litre. This plasma concentration is lower than the concentration that proponents of plasma methadone monitoring recommend as the appropriate target concentration during methadone maintenance treatment. This is a salutary illustration of the dangers of attempting to interpret postmortem blood concentrations using data acquired from studies of therapeutic concentrations in the living. The Manchester group found much higher methadone concentrations in their series, but it is not clear from what body site their samples were collected. ${ }^{21}$ Although postmortem methadone concentrations are frequently below the target plasma concentrations aimed at in clinical practice, the population that the pathologist sees is frequently not the same as that of the clinician caring for problem drug misusers. This has already been pointed out with respect to opiate naive users. These people are more likely to have no tolerance to opiates, including methadone, and the quantities that they ingest are not regulated. When given (diverted) methadone they appear particularly sensitive to this drug. The data from Denmark also point to the vulnerability of opiate naive people. The deaths of people not in a maintenance programme were characterised by lower mean and median methadone concentrations than the deaths of people under methadone treatment. ${ }^{14}$ Another problem that may be encountered is loss of tolerance. This is particularly recognised in prisoners recently released from prison, where tolerance to opiates is lost by enforced partial or total abstinence. $^{22} 23$ Thus, although postmortem redistribution phenomena might account for the relatively low concentrations of methadone found in those dying of methadone overdose, differences in the populations cared for by clinicians and investigated by pathologists are also likely to be important.

In those victims who engage in polydrug use the methadone itself may not be enough to cause death, but the use of other drugs, particularly respiratory depressants, will have an additive effect and increase the risk of death. In cases where polydrug use occurs, it can be difficult to determine what proportion any individual drug plays in a death. The practice of individual pathologists will vary. In some cases, a low concentration of a benzodiazepine will be ignored, but other pathologists will include all drugs in the cause of death because they might have an additive effect. In some cases, the pathologist is faced with a combina- tion of respiratory depressants and stimulants. In such cases, an argument can be advanced that the stimulant does not contribute to death. However an alternative argument can be advanced that the interactions and subsequent effects of multiple drugs are unpredictable and all significantly measurable drugs should be included in the cause of death. There is no easy answer to this problem. In a study from Edinburgh, in 38 deaths only methadone was found, with methadone and other drugs being found in 26 deaths. ${ }^{19}$ Polydrug use was a feature in a series of methadone deaths seen in Strathclyde. $^{22}$

The data on childhood deaths are limited. The five cases seen in our study had methadone concentrations between 200 and $489 \mu \mathrm{g} /$ litre. In two deaths reported by Smialek and colleagues of a 1 year old boy and a 3 year old girl both had methadone concentrations of $110 \mu \mathrm{g} /$ litre. ${ }^{24}$ These findings support the opinion that only relatively small amounts of methadone are required to kill a child.

In deaths with very low or absent blood concentrations of methadone, methadone might still play a part. Methadone might cause a prolonged period of unconsciousness that then leads to inhalational pneumonia, which is a common finding in methadone deaths. In our study, $32 \%$ of all deaths had evidence of bronchopneumonia. This was even more common in methadone only deaths, where $45 \%$ of cases had evidence of bronchopneumonia. This evidence supports the view that methadone only deaths are slower than many polydrug deaths, where only $20 \%$ of deaths showed evidence of bronchopneumonia. Methadone might be metabolised during the period of prolonged unconsciousness and this might account for what appears to be a low fatal concentration. These findings might have an important message for drug users in that deaths appear to be relatively slow in many cases and may be reversible with appropriate medical treatment. Deaths from injection of methadone are likely to be quicker than when the drug is administered orally.

In the minefield of interpretation of postmortem data the problem of redistribution and site dependence of drugs is becoming increasingly recognised. Levine and colleagues examined the postmortem site dependence of methadone. ${ }^{25}$ They examined heart blood in 15 cases, and an alternative sample in each case. In nine cases subclavian blood was examined. The ratio of subclavian to heart blood varied from 0.30 to 2.03. A similar variation was found in pericardial fluid (0.47 to 1.87 ) and inferior vena cava and femoral blood (0.81 to 4.13). Prouty and Anderson found less variation in an examination of five cases. ${ }^{26}$ In our study of 26 cases, there was a variation of over $100 \%$ between arm and leg samples in some cases. In the study of Levine et al no particular site emerged as the preferred choice. The data from our study, using peripheral blood from the arm and leg, do not indicate any preferred site either. However, we would support a general policy of collection of blood for toxicology from the femoral vein. ${ }^{27}$ 
There are several explanations for the variation in postmortem concentrations. Diffusion from the stomach is possible and this might affect concentrations in heart blood. Compounding this is the problem of release of methadone from the liver, which again might affect blood concentrations. Movement of methadone from other tissues to blood and vice versa all contribute to the problems of determining an accurate concentration of methadone in relation to the cause of death. The distribution of methadone might also depend on whether methadone has been injected. This is not always easy to determine, because injection of heroin might occur at the same time as methadone is ingested. In addition, methadone might be injected. Drawing blood back into the syringe before injecting another substance may cause traces of methadone in that syringe. Some evidence points to higher concentrations of methadone after injection compared with ingestion. ${ }^{13}$ Examination of stomach contents might provide evidence of the method of administration. In our series, $64 \%$ of cases had methadone detected in the stomach at a concentration of less than $10 \mathrm{mg} /$ litre. Very few cases had none detected. In the other cases, methadone was present in the stomach contents at a concentration above $10 \mathrm{mg} /$ litre. A high blood methadone concentration in the presence of trace amounts in the stomach and the presence of injection marks might support the contention that methadone was injected. A low concentration of methadone in the stomach contents might represent backwash of methadone containing bile into the stomach, and cannot be assumed to be the result of oral ingestion. If the issue is important, measurement of conjugated methadone in stomach contents could be performed, although this is not a routine test. Methadone in stomach content above $10 \mathrm{mg} /$ litre is, in our opinion, evidence of oral ingestion.

Overall, in identifying a cause of death, the pathologist must interpret all data available, including microscopic and toxicological data, recognising the phenomenon of postmortem redistribution and site dependence. To a certain extent, postmortem toxicology must be recognised as a qualitative rather than a quantitative analysis. Our practice is to take peripheral blood as the most appropriate sample, along with urine and stomach contents. Other protocols include multiple peripheral blood and organ site sampling. However, apart from the question of expense, the evidence so far is that multiple site sampling does not assist in determining a poisonous versus therapeutic concentration, although such site sampling might be useful in certain cases.

In conclusion, postmortem toxicological examination seems to confirm that there is an overlap between clinical therapeutic concentra- tions and those that cause death. There are problems with site dependence and postmortem redistribution. However, the pathologist has the advantage of examining the whole body, and can interpret the toxicological findings in context. We are satisfied that methadone poisening deaths are not overestimated.

1 Dole VP, Nyswander M. A medical treatment for diacetylmorphine (heroin) addiction. $\mathcal{F} A M A$ 1965;193:80-4.

2 Nadelmann E, McNeeley J, Ducker E. International perspectives. In: Lowinson JH, Ruiz P, Millman RB, et al, eds. Substance abuse. A comprehensive textbo

3 Kreek MJ, Reisinger M. The addict as a patient. In: Lowinson JH, Ruiz P, Millman RB, et al, eds. Substance abuse. A comprehensive textbook, 3rd ed. London: Williams and Wilkins, 1997:822-53.

4 Neeleman J, Farrell M. Fatal methadone and heroin overdoses: time trends in England and Wales. F Epidemiol overdoses: time trends in England

5 Strang J, Sheridan J, Barber N. Prescribing injectable and oral methadone to opiate addicts: results from the 1995 national postal survey of community pharmacies in England and Wales. BMF 1996;313:270-2.

6 Dole VP. Implications of methadone maintenance for theories of narcotic addiction. $\mathcal{F A M A}$ 1988;260:3025-9.

7 Loimer N, Schmid R. The use of plasma levels to optimise maintenance treatment. Drug Alcohol Depend 1992;30:241.

8 Loimer N, Schmid R, Grunberger J, et al. Psychophysiological reactions in methadone maintenance patients do not correlate with methadone plasma levels. Psychopharmacology (Berl) 1991;103:538.

9 Robinson AE, Williams FM. The distribution of methadone Robinson AE, Williams FM. The distribution
in man. F Pharm Pharmacol 1971;23:353-8.

10 Irey NS, Froede RC. Evaluation of deaths from drug overdose: a clinico-pathologic study. Am $\mathcal{F}$ Clin Pathol 1974;61:778-84.

11 Drummer OH, Opeskin K, Syrjanen M, et al. Methadone toxicity causing death in ten subjects starting on a methadone maintenance program. Am f Forensic Med Pathol 1992;13:346-50.

12 Barrett DH, Luk AJ, Parrish RG, et al. An investigation of medical examiner cases in which methadone was detected, Harris County, Texas: 1987-1992. F Forensic Sci 1995;41: 442-8.

13 Segal RJ, Catherman RL. Methadone-a cause of death. $\mathcal{F}$ Forensic Sci 1974;19:575-84.

14 Worm K, Steentoft A, Krinsholm B. Methadone and drug addicts. Int $\mathcal{F}$ Legal Med 1993;106:119-23.

15 Merril J, Garvey T, Rosson C. Methadone treatment: methadone concentrations taken as indicating deaths due to overdose need to be reviewed. BMF 1996;313:1481.

16 Greene MH, Luke JL, DuPont RL. Opiate overdose deaths in the district of Columbia. Part II-methadone-related fatalities. F Forensic Sci 1974;19:575-84

17 Clark JC, Milroy CM, Forrest ARWF. Deaths from methadone use. Fournal of Clinical Forensic Medicine 1995;2: 143-4.

18 Cairns A, Roberts ISD, Benbow EW. Characteristics of fatal methadone overdose in Manchester, 1985-94. BMF 1996; 313:264-5.

19 Bentley AJ, Busuttil A. Deaths among drug abusers in South-East Scotland (1989-1994). Med Sci Law 1996;36: 231-6.

20 Greenwood J, Zealley H, Gormon D, et al. Deaths related to methadone have doubled in Lothian. BMF 1997;314:1763.

1 Benbow EW, Roberts ISD, Cairns A. Fatal methadone overdose. BMF 1997;314:975.

22 Cooper GAA, Seymour A, Cassidy MT, et al. A study of methadone fatalities in the Strathclyde region. Med Sci Law 1999;39:233-42.

23 Seaman SR, Brettle RP, Gore SM. Mortality from overdose among injecting drugs users recently released from prison: database linkage study. BMF 1998;316:426-8.

24 Smialek JE, Monteforte JR, Aronow R, et al. Methadone deaths in childhood. FAMA 1977;238:2516-17.

25 Levine B, Wu SC, Dixon A, et al. Site dependence of postmortem blood methadone concentrations. Am f Forensic Med Pathol 1995;16:97-100.

26 Prouty RW, Anderson WH. The forensic implications and temporal influences on post-mortem blood-drug concentrations. F Forensic Sci 1990;35:243-70.

27 Forrest ARW. ACP Broadsheet No 137. Obtaining samples at post mortem examination for toxicological and biochemical analyses. F Clin Pathol 1993;46:292-6. 